\title{
Bilateral Mammary Tuberculosis Associated with a Borderline Ovarian Tumor
}

\author{
Joachim Van Keirsbilck ${ }^{\mathrm{a}} \quad$ Ine Riphagen ${ }^{\mathrm{a}}$ Hans Struyven $^{\mathrm{b}} \quad$ Andre Van den Eeckhout $^{\mathrm{c}}$ \\ Ann Cornelis ${ }^{\mathrm{d}}$ Patrick Neven ${ }^{\mathrm{e}}$ Frederic Amant ${ }^{\mathrm{e}}$ Ignace Vergote $^{\mathrm{e}}$ \\ a Department of Obstetrics and Gynecology, \\ ${ }^{b}$ Department of Internal Medicine, Pulmonary Diseases, R.Z. Heilig Hart, Tienen, \\ ${ }^{\mathrm{c}}$ Department of Internal Medicine, Pulmonary Diseases, University Hospitals Leuven, Katholieke Universiteit Leuven, \\ ${ }^{\mathrm{d}}$ Department of Pathology, R.Z. Heilig Hart, Tienen, \\ e Department of Obstetrics and Gynecology, Division of Gynecologic Oncology and Breast Centre, University Hospitals Leuven, \\ Katholieke Universiteit Leuven, Belgium
}

\section{Key Words}

Breast tuberculosis · Borderline ovarian cancer .

Mammography $\cdot$ Breast disease

\section{Summary}

Background: Mammary tuberculosis is rare in the Western world. It has no defined clinical or imaging features, and has to be differentiated from breast cancer and an abscess. Case Report: We present a case of mammary tuberculosis combined with borderline ovarian cancer. The bilateral breast tuberculosis was the first and only symptom of underlying tuberculosis with Ziehl-Neelsenpositive para-aortic lymph nodes. During further exploration, an asymptomatic pelvic mass was discovered, which appeared later to be a borderline ovarian tumor. The patient was treated with tuberculostatic therapy for 6 months, resulting in a complete regression of the breast lesions. She also underwent hysterectomy with bilateral salpingo-oophorectomy and lymph node dissection for her ovarian cancer. Conclusions: This case report emphasizes that breast tuberculosis should be included in the differential diagnosis of any atypical breast mass.

\section{Introduction}

Tuberculosis of the breast is a rare entity in Western countries. Since the report of the first case by Sir Astley Cooper in 1892 ,

\section{Schlüsselwörter \\ Brusttuberkulose - Borderline-Ovarialkarzinom . Mammographie · Erkrankung der Brust}

\section{Zusammenfassung}

Hintergrund: Brusttuberkulose tritt in der westlichen Welt nur selten auf. Die Erkrankung besitzt keine klar definierten Eigenschaften in der klinischen oder bildgebenden Untersuchung und muss von Brustkrebs sowie Abszessen unterschieden werden. Fallbericht: Wir berichten von einer Patientin mit Brusttuberkulose kombiniert mit einem Borderline-Ovarialkarzinom. Die bilaterale Brusttuberkulose war das erste und einzige Symptom einer tuberkulösen Grunderkrankung mit Ziehl-Nielsenpositiven paraaortalen Lymphknoten. Die weitere Untersuchung ergab eine asymptomatische Neoplasie im Beckenbereich, welche sich später als ein BorderlineOvarialkarzinom darstellte. Die Patientin wurde 6 Monate lang mit Tuberkulostatika behandelt, woraufhin sich die Brustknoten komplett zurückbildeten. Zur Behandlung des Ovarialkarzinoms wurden außerdem eine Hysterektomie mit beidseitiger Salpingo-Oophorektomie sowie Lymphknotenentfernung durchgeführt. Schlussfolgerungen: Dieser Fallbericht zeigt, dass Brusttuberkulose Bestandteil der Differentialdiagnose bei atypischen Brusttumoren sein sollte.

over 900 cases have been published in the literature $[1,2]$. The worldwide incidence of mammary tuberculosis varies between 0.1 and $0.52 \%$ of all breast diseases. In the developing world, such as India, the incidence is up to $3 \%$ [1]. In developed

\begin{tabular}{ll}
\hline KARGER & @ 2008 S. Karger GmbH, Freiburg \\
Fax +49 7614520714 & Accessible online at: \\
$\begin{array}{l}\text { E-mail Information@Karger.de } \\
\text { www.karger.com }\end{array}$ & www.karger.com/brc
\end{tabular}


countries, a recent increase has been noticed, probably due to the increasing number of immunocompromised patients (acquired immune deficiency syndrome, AIDS) and to immigration from tuberculosis-endemic regions [3]. Breast tuberculosis is classified in primary or secondary disease. The diagnosis is hampered by the quasi identical signs and symptoms for breast carcinoma or breast abscess [1-3].

\section{Case Report}

A 62-year-old Caucasian female patient presented with bilateral palpable breast masses which she discovered several weeks ago. Her medical history included Hodgkin's lymphoma at the age of 22, which was cured with chemotherapy and radiotherapy. The patient mentioned a weight loss of $8 \mathrm{~kg}$ over the previous 3 months. Physical examination revealed a firm and clearly defined mass of $3 \mathrm{~cm}$ in the right breast, and a $3.5 \mathrm{~cm}$ nodule with poorly defined margins in the left breast. The axillary, supra-, and infraclavicular lymph node regions were normal on palpation. There was no skin or nipple retraction. The serum tumor marker CA 15.3 was $15 \mathrm{U} / \mathrm{ml}$ (upper normal limit < $30 \mathrm{U} / \mathrm{ml}$ ). Mammography, ultrasound, and magnetic resonance imaging (MRI) showed a dense area of $5 \mathrm{~cm}$ with indistinct margins in the upper inner quadrant of the left breast, and in the upper outer part of the right breast (fig. 1). A sonographically guided core biopsy showed an extensive granulomatous inflammatory reaction, without signs of malignancy. A Mantoux test provoked a red, raised induration of $6 \mathrm{~cm}$ at the point of injection. Further pneumological examinations, including chest X-ray and thoracic computed tomography (CT), showed no signs for tuberculosis or other interstitial pulmonary disease.

On gynecological examination, a firm, mobile, 20-cm pelvic mass was palpated. Vaginal ultrasound showed bilaterally enlarged ovaries (right: $5.8 \times 5.5 \times 8.3 \mathrm{~cm}$; left: $10.7 \times 9.9 \times 14.6 \mathrm{~cm})$. Both ovaries were multilocular with solid regions and an irregular inner wall. The images were suggestive for a bilateral, malignant ovarian process. The serum tumor marker CA 125 was $429 \mathrm{U} / \mathrm{ml}$ (upper normal limit < $35 \mathrm{U} / \mathrm{ml}$ ), and the CA 19.9 was $345 \mathrm{U} / \mathrm{ml}$ (upper normal limit <37 U/ml). An abdominal CT scan showed a polylobulated, solid, adnexal mass, without vaginal or parametrial involvement. In the left para-aortic region, a slightly enlarged lymph node was observed, also positive on positron emission tomography (PET) scan. There was bilateral thoracic hypermetabolism on PET scan compatible with tuberculous mastitis. Multiple biopsies and cultures obtained during laparoscopic exploration showed no evidence of peritoneal malignancy. The culture of peritoneal fluid for Mycobacterium remained negative. Because ovarian cancer could not be excluded and because of the enlarged para-aortic lymph nodes, a total hysterectomy with bilateral salpingo-oophorectomy with frozen section was performed, followed by omentectomy, pelvic and para-aortic lymph node dissection, and peritoneal biopsies. The final pathological result was a bilateral serous borderline ovarian tumor, probably originating from a superficial cystadenofibroma. All 55 lymph nodes were negative for malignancy, but 14 showed granulomatous inflammation with central necrosis. Ziehl-Nielson staining showed acid-fast bacilli, demonstrating active tuberculosis (fig. 2).

The patient was referred to the Department of Infectious Diseases for tuberculostatic therapy. The treatment included isoniazide $300 \mathrm{mg} / \mathrm{day}$, rifampicine $600 \mathrm{mg} / \mathrm{day}$, pyrazinamide 1,500 mg/day, and pyridoxine hydrochloride $250 \mathrm{mg} /$ week, for the first 2 months; followed by isoniazide $300 \mathrm{mg} /$ day, ethambutol dihydrochloride $1,200 \mathrm{mg} /$ day, and pyridoxine hydrochloride $250 \mathrm{mg} /$ week, for the last 4 months. The patient was seen for control clinical examination and mammography after 6 months of therapy. She was doing well and had no further complaints. Follow-up mammography and ultrasound of the breasts did not show anymore signs of tuberculosis (fig. 1).

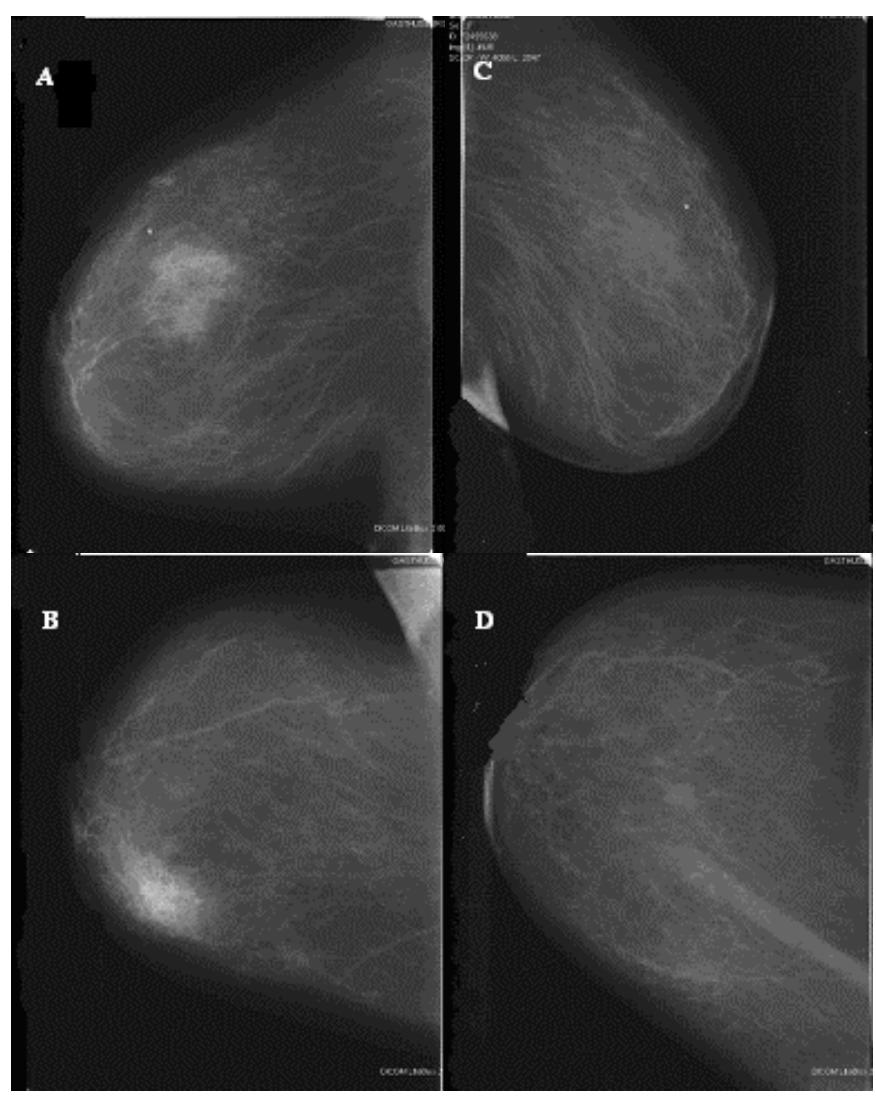

Fig. 1. Mammography: a dense, ill defined and lobulated mass of $5 \mathrm{~cm}$ with indistinct margins $\mathbf{A}$ in the upper outer right quadrant, as well as $\mathbf{B}$ in the upper inner left part of the breasts. A control mammography after 6 months of tuberculostatic therapy showed no signs of tuberculosis in $\mathbf{C}$ the right breast, and $\mathbf{D}$ the left breast.

\section{Conclusions}

Mammary tuberculosis is seen quite rarely in Western countries. Although the overall incidence ranges between 0.1 and $0.5 \%$, it increases to up to $3 \%$ of all breast diseases in tuberculosis endemic regions [1]. Although the vast majority of patients with breast tuberculosis are women, it occurs in $4 \%$ of the male population. Bilateral involvement is seen in $3 \%$. The population at risk are young (21-30 years), pregnant, and multiparous women [1,3]. Mammary tuberculosis is classified as a primary or secondary disease. Breast tissue is relatively resistant to Koch's bacilli, because of the local hostile environment, as are the skeletal muscles and spleen [3]. Primary tuberculosis occurs in the absence of any other tuberculous lesion. This uncommon type of infection is probably due to direct inoculation through skin abrasions or duct openings in the nipples [4]. The infected faucial tonsils of suckling infants have been suggested to be a cause of tuberculosis in lactating breasts [1]. Secondary mammary tuberculosis has multiple possible ways of spreading. The retrograde lymphatic spread from the axillary glands (Cooper's theory) is the most common hypothesis, although tracheobronchial, paratracheal, 


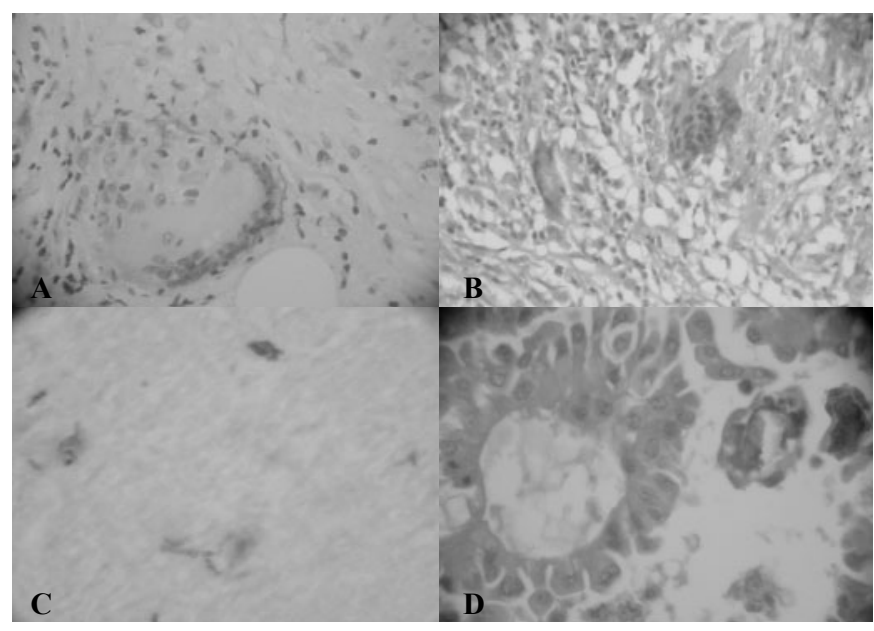

Fig. 2. A Photomicrograph showing a granulomatous inflammation with epithelioid and Langerhans' giant cells; $\mathbf{B}$ foci of central necrosis were present in the para-aortic lymph nodes; C Ziehl-Neelsen staining shows acid-fast bacilli, demonstrating active tuberculosis; $\mathbf{D}$ borderline cystadenofibroma present in both ovaries.

mediastinal, and internal mammary lymph nodes may also be at the origin of the breast disease. Hematogenous spread is suggested to occur in the highly vascularized lactating breasts. Direct extension from contiguous structures, such as an infected rib, a cartilage or tuberculous pleuritis, has also been reported [1-4]. In our case, no evidence for any spreading type could be found. There were only 2 sites of tuberculosis: the breasts and the para-aortic lymph nodes.

The clinical presentation of breast tuberculosis shows great similarity to a mammary carcinoma or a breast abscess. As in our patient, the majority of patients present with a firm, mobile, ill defined and irregular breast lump in the upper and outer quadrants of the breasts. Tuberculosis ulcers or abscesses are common. Associated general symptoms of tuberculosis like fever, anorexia, weight loss, and night sweats are not always present [3]. Nipple retraction and 'peau d'orange' are usually signs of malignancy [1]. On the other hand, mammary tuberculosis does not exclude concomitant breast cancer. Breast tuberculosis can be classified into 3 types: nodular, diffuse, and sclerosing. The nodulocaseous variety is the most common form, presenting as a well circumscribed, slowly growing, painless mass [1]. The diffuse form shows a dense breast with multiple foci, associated sinus formation, and skin thickening [5]. The sclerosing pattern creates a hard, slowly growing, painless lump with excessive fibrosis and sometimes nipple retraction and usually occurs in older females with involuting breasts [1].

The diagnosis of mammary tuberculosis is difficult. No imaging technique is specific for tuberculosis. The radiological investigations are more helpful in defining the extent of the lesion than in the diagnosis itself. The mammographic findings are dense, ill defined breast masses with or without thickened skin [6]. Ultrasonography of the breasts shows heterogeneous, hypoechoic, irregularly bordered masses with internal echoes. Cystic lesions, posterior acoustic enhancement, or fistulas may also be present [5]. CT and MRI of the breasts are of value in demonstrating the extra-mammary extent of the disease $[1,7]$. Pathological examination of breast tissue, obtained most frequently by fine needle aspiration cytology (FNAC), core needle, or open biopsy, is of great importance for diagnosing tuberculosis. On cytology, epithelioid granulomas, Langerhans' giant cells, and lymphohistiocytic aggregates are observed [1-3]. Other types of granulomatous inflammation, such as sarcoidosis, actinomycosis, fungal infections, fat necrosis, and plasma cell mastitis, have to be considered in the differential diagnosis [1-4]. Culture of Mycobacterium is hampered by the required time and the frequent false negative results. In the presented case, Ziehl-Nielson staining showed acid-fast bacilli, but that is not always the case [8]. A positive Mantoux test demonstrates only that a person has been exposed to tubercle bacilli [1]. Most of these techniques are of no practical use in less developed countries. Above all, the diagnosis of mammary tuberculosis is only possible if the clinician keeps a high degree of suspicion.

The gold standard in the treatment of breast tuberculosis includes ethambutol, rifampicine, isoniazide, and pyrazinamide [1]. Surgery has no significant role in the treatment of tuberculosis. Minimal surgical interventions may be indicated for diagnostic reasons (open biopsies), for the drainage of an abscess, or to excise residual sinuses or masses. This must always be followed by tuberculostatic therapy. Otherwise, reappearance and/or persistence will occur [4].

The ovarian borderline tumor diagnosed in this case is probably purely coincidental. The patient had a history of Hodgkin's lymphoma treated with chemotherapy and radiotherapy. The elevated long-term risk for second malignancy, even after more than 20 years follow-up, is well known in survivors of Hodgkin's disease treated during adolescence or young adulthood. Van Leeuwen et al. [9] reported a relative risk of 4.1 (95\% confidence interval: $1.7-8.5)$ for secondary female genital malignancies. Because of the abdominal mass, the ascites, and the elevated serum CA 125, ovarian malignancy was suspected in our case [10]. Because tuberculosis may mimic ovarian malignancy, it is important to confirm the diagnosis of cancer and to exclude peritoneal and/or ovarian tuberculosis before proceeding with radical surgery.

In summary, breast tuberculosis is an extremely rare finding in a postmenopausal Caucasian woman living in Western Europe. Because of the increasing prevalence of tuberculosis in the developed world, mammary tuberculosis should be included in the differential diagnosis of breast lesions even in postmenopausal women.
202

Breast Care 2008;3:200-203
Van Keirsbilck/Riphagen/Struyven/ Van den Eeckhout/Cornelis/Neven/Amant/ Vergote 


\section{References}

1 Tewari M, Shukla HS. Breast tuberculosis: diagnosis, clinical features and management. Indian J Med Res 2005;122,103-110.

$\checkmark 2$ Hassouna JB, Gamoudi A, Bouzaiene H, Dhiab T, et al.: Mammary tuberculosis: a retrospective study of 65 cases. Gynecol Obstet and Fertil 2005;33:870876

3 Harris SH, Khan MA, Khan R, Haque F, et al: Mammary tuberculosis: analysis of thirty-eight patients. ANZ J Surg 2006;76:234-237.

4 Khanna R, Prasanna GV, Gupta P, Kumar M, et al.: Mammary tuberculosis: report on 52 cases. Postgrad Med J 2002;78:422-424.

5 Kervanciolgu S, Kervancioglu R, Özkur A, Sirikçi A: Primary tuberculosis of the breast. Diagn Interv Radiol 2005;11:210-212.

6 Sabaté J, Clotet M, Gomez A, De las Heras P, et al.: Radiologic evaluation of uncommon inflammatory and reactive breast disorders. Radiographics 2005; 25:411-424.

7 Fellah L, Leconte I, Weynand B, Donnez J, et al.: Breast tuberculosis imaging. Fertil Steril 2006;86: 460-461.

8 Verfaillie G, Goossens A, Lamote J: Atypical mycobacterium breast infection. Breast J 2004;10:60

9 Van Leeuwen F, Klokman WJ, Veer MB, Hagenbeek A, et al.: Long-term risk of second malignancy in survivors of Hodgkin's disease treated during adolescence or young adulthood. J Clin Oncol 2000;18:487-497.

10 Koc S, Beydilli G, Tulunay G, Ocalan R, et al.: Peritoneal tuberculosis mimicking advanced ovarian cancer: a retrospective review of 22 cases. Gyn Oncol 2006;103:565-569. 